\title{
Review of QTRA and Risk-based Cost-benefit Assessment of Tree Management
}

\author{
Mark G. Stewart, Dealga O'Callaghan, and Mark Hartley
}

\begin{abstract}
Quantified Risk Assessment (QRA) has been in wide use in risk management since the 1960s for systems ranging from aviation, nuclear power, and offshore platforms to medical treatment and pharmaceuticals. The Quantified Tree Risk Assessment (QTRA) system is examined considering the principles of QRA. A case study of 14 fig trees in Newcastle, Australia, illustrates some limitations of the QTRA process, and extrapolating risks for a single tree to a group of trees. There is a need for any risk management process involving trees, not only to assess the risk, but to weigh the benefits provided by trees by a risk-based cost-benefit analysis. Tree risk assessors should rely on benchmarks to ensure that their assessment is not outside of the realms of reality or scientific rigor.

Key Words. Australia; Cost-benefit Analysis; Quantified Tree Risk Assessment; Risk; Risk Management; Trees.
\end{abstract}

An important aspect of tree management is to assess the likelihood of a tree causing harm (e.g., injury, death, property damage, disruption of activities). In recent years, the potential for trees to cause harm has been highlighted by elevated media coverage of tree caused injuries or fatalities. The reality, however, is that the risk of being killed or injured by a tree is extremely low. For example, about three people per year in the United Kingdom are killed by trees in public places, and the fatality risk per tree is 1 in 150 million for all trees in the UK, or 1 in 10 million for trees in or adjacent to areas of high public use (HSE 2007; NTSG 2011). In the United States, there were 407 deaths from wind-related tree failures in the 13 year period 1995-2007 (Schmidlin 2009) or 31 fatalities per year (note that the U.S. population is five times that of the UK).

There has been much debate about the risk trees pose to human populations. In the UK, the debate was heightened following a high profile case, Poll v. Bartholomew (2006), which involved a motorcyclist being hurt by a tree that failed. It was never clarified as to whether the tree fell on to Mr. Poll or he came around the corner on his bike and collided with the fallen tree. In any event, he sustained personal injuries. In this case, the court decided that a large private estate did not have an adequate system for the inspection and management of trees, which was an annual drive/ walk by assessment. The court concluded that inspections should be undertaken by qualified and competent inspectors. Speculation that this judgment placed an excessive burden of tree inspections on landowners created an air of anxiety. This resulted in much uncertainty and many trees being unnecessarily felled for fear of litigation (e.g., NTSG 2011). This understandably made decision makers more risk averse than they otherwise might have been.

Systems have been developed to try to assess the likelihood of trees failing, and the harm that might be caused in the event of failure. Matheny and Clark (1994) developed a hazard evaluation system that assigns a numerical value between 1 and 4, for (i) failure potential, (ii) size of part, and (iii) target rating, which are then totaled to produce a hazard rating between 3 and 12. Other tree risk assessment systems include: THREATS \& THREATS-NR (www. flac.uk.com), The Bartlett Tree Expert Company's Tree Risk Management 2nd Edition (Smiley et al. 2007), and the ISA's Best Management Practice for Tree Risk Assessment (Smiley et al. 2011).

Ellison (2005) took a probabilistic approach to risk and developed the Quantified Tree Risk Assessment (QTRA) system. This system attempts to provide a quantitative framework for the assessment of the three components of tree risk: (i) target value, (ii) probability of failure, and (iii) impact potential. The system assesses the probabilities of the three components of risk and calculates their product, which allows skilled tree inspectors to quantify the risk of harm from tree failure, which in turn facilitates the balance between tree safety and tree value.

Quantified Risk Assessment (QRA) has been in wide use in risk management since the 1960s. QRA assesses hazard likelihood and system vulnerability using sound physical modeling of failure processes and recognition of uncertainty and variability of influencing variables. This is absent from the QTRA system, which seems to rely more on subjective assessments, particularly for probability of tree failure. Moreover, the QTRA system does not consider benefits in the risk assessment component where costs and benefits are compared, but rather relegates this to information contained in the practice notes.

In principle, QTRA is a welcome development because a quantified risk-based approach to tree management is based on sound decision-support principles. This paper explains the principles of QRA, and identifies some weaknesses in the QTRA process that could be rectified by the incorporation of additional QRA principles in any revision of QTRA. The paper will also show how a cost-benefit analysis 
that considers risk of harm, costs of tree removal, benefits of tree amenity, and other costs and benefits can be used to compare costs and benefits in a rigorous manner. This type of risk and economic assessment can better inform decision-makers.

\section{QUANTIFIED TREE RISK ASSESSMENT}

The QTRA process was developed and documented by Ellison (2005) and the Quantified Tree Risk Assessment User Manual V3.06 (2012). Risk of harm (ROH) is calculated as (Ellison 2005):

[1] Risk of harm $=$ Probability of failure $\times$ Target value $\times$ Impact potential

where harm is defined as serious injury or death; probability of failure is the annual probability that a tree or selected tree part will fail; the target value is the probability that a person, a vehicle, or the property will be impacted; and the impact potential is the probability of harm a falling tree, or part of a tree, can cause to a pedestrian or vehicle. The risk is deemed "unacceptable" if the ROH exceeds 1 in 10,000 .

\section{Case Study: Laman Street Fig Trees in Newcastle}

The City of Newcastle in New South Wales, Australia, had 17 mature fig trees (Ficus microcarpa var. hillii (Hill's weeping fig) on both sides of Laman Street in the heart of the city (Figure 1). These trees were estimated to be in excess of 70 years of age. They have been topped on multiple occasions. Over the last few decades, however, topping has ceased and the trees were left unpruned. Although growing in confined openings between the street and sidewalk, the trees were considered to have good health and vitality. Some of the trees had started to partially grow over the adjacent hard surfaces.

In June 2007, a severe east coast weather movement caused wind speeds of $124 \mathrm{~km} / \mathrm{hr}$ and intense rainfall. As a result, gaps appeared between the base of the four trees and the adjacent hard surfaces (Figure 2). Without any further testing, three of these trees were removed. The fourth tree that was thought to have moved was monitored over the following month to check for further movement. This tree was then determined by Newcastle City Council (NCC) to be stable, and was subsequently retained. It is important to be aware that, even if the trees had moved, this movement would not have harmed people or property.

In August 2009, NCC engaged a consultant to assess the stability and safety of the remaining 14 trees. The Stage 1 Visual Tree Assessment concluded that the trees be removed within five years (Marsden 2009). In response, NCC sought to have the risk posed by the trees assessed in order to determine an appropriate management strategy.

In September 2009, a Quantified Tree Risk Assessment was prepared for Newcastle City Council. It concluded that the risk of harm was 1 in 19.8 per tree per year, and that the probability of tree failure was 1 in 7.5 per tree per year (Table 1). A subsequent report by another arboricultural consultant reviewed this first QTRA report and concluded in 2010 that, "On review, I believe that this report provides a reasonable assessment of the quantified risk of harm" (QTRA Newcastle 2010). Both consultants were licensed QTRA practitioners. Since the ROH

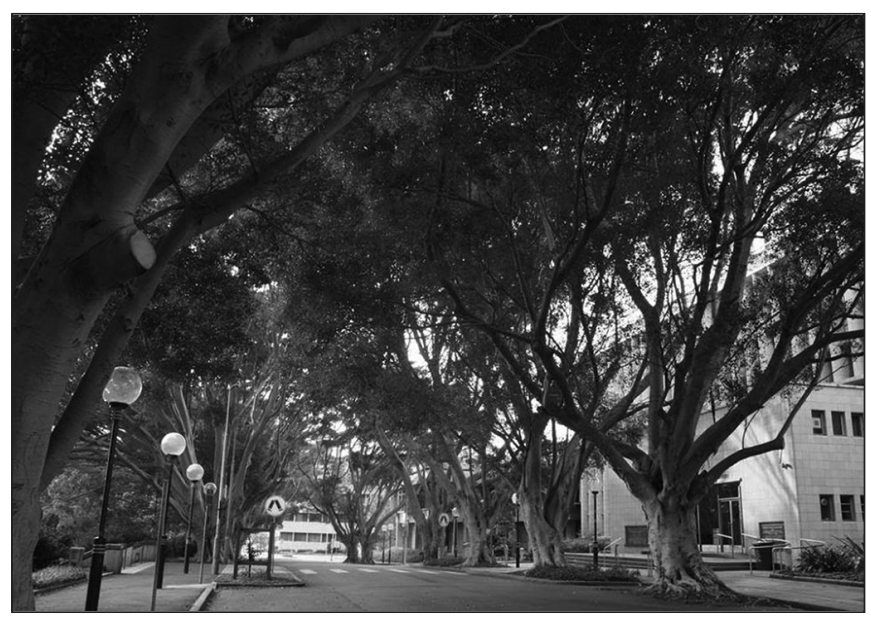

Figure 1. Laman Street looking east, April 2010.

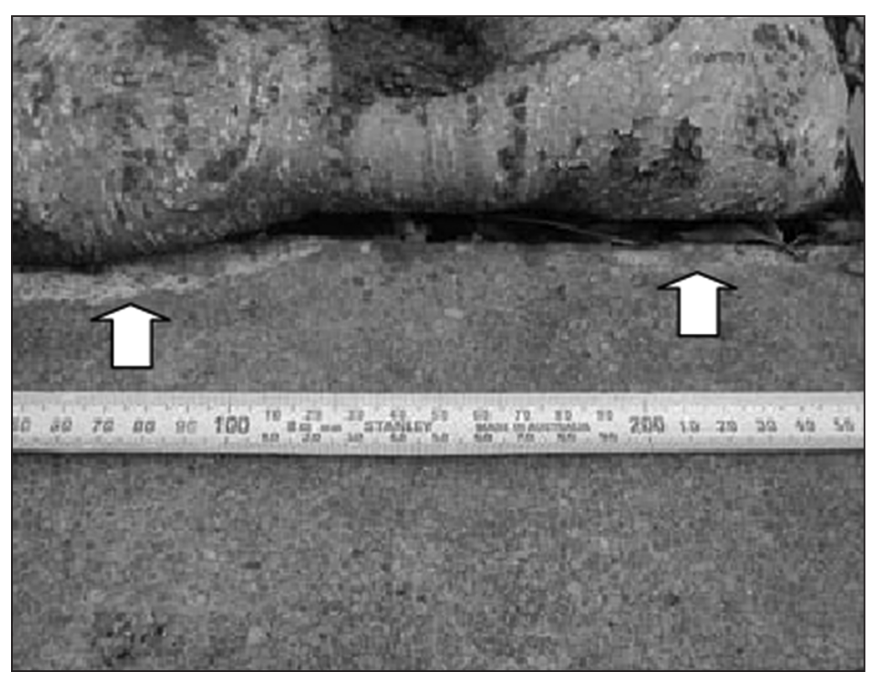

Figure 2. The gap observed between one of the trees and the adjacent hard surface (Marsden 2007).

exceeded the QTRA suggested ROH threshold of 1 in 10,000, the reports declared the level of risk as "unacceptable." Based on the level of risk, NCC made a decision to remove the trees in late 2011, and the trees were finally removed in February 2012.

These 14 remaining trees survived for over 4.5 years (June 2007 to February 2012) before they were eventually removed. Tree failures on Laman Street were isolated events (i.e., one or two trees may fail but not all trees at the same time) due to the highly variable nature of root conditions and wind environment. In the absence of evidence to the contrary, these trees can be treated as statistically independent. Using QTRA, the formula for determining fatalities in this scenario is

$$
\mathrm{E}=\mathrm{N} \times \mathrm{ROH} \times \mathrm{T}
$$

where $\mathrm{N}$ is the number of trees $(\mathrm{N}=14)$, and $\mathrm{T}$ is the time period in years $(T=4.5)$. Using the QTRA results, the expected (average) number of deaths or serious injuries (E) in four and a half years between the storm and tree removal is calculated as follows: $14 \times 1 / 19.8 \times 4.5=3.2$. 
Similarly, the expected (average) number of failures in four and a half years is determined here

$$
\mathrm{E}=\mathrm{N} \times \operatorname{Pr} \times \mathrm{T}
$$

where $\mathrm{Pr}$ is the QTRA probability of tree failure per tree per year. QTRA results therefore indicate the following: $14 \times 1 / 7.5 \times 4.5=8.4$ tree failures.

The formula for determining the probability that no tree should fail in four and a half years is

[4] $\operatorname{Pr}($ no tree failures $)=[1-\operatorname{Pr}(\text { tree failure })]^{\mathrm{N} \times \text { time }}$

which results in the following: $(1-1 / 7.5)^{14} \times 4.5=$ $0.012 \%$, or $1 / 8,000$. The probability that at least one tree will fail in four and a half years is

[5] $\operatorname{Pr}($ at least one tree failure $)=1-[1-\operatorname{Pr}(\text { tree failure })]^{\mathrm{N} \times \text { time }}$

which results in the following: $1-(1-1 / 7.5)^{14 \times 4.5}=99.99 \%$. Such probabilistic analyses were not included in the consultant reports prepared for NCC. Likewise, these statistics appear not to have been considered and/or appropriately weighed by NCC in making the decision to remove the trees. This type of analysis enables a kind of reality check when extrapolating rates of failure and harm for a single tree to a group of trees. These analyses indicate that the $\mathrm{ROH}$ provided to NCC by the QTRA assessors were excessively high. Moreover, all 14 trees remained upright, despite a predicted $99.99 \%$ probability that at least one tree would fail in a 4.5-year period.

A risk of death (or harm) per tree per year of 1 in 19.8 is the highest estimate observed by the lead author for any activity. A single fig tree in Laman Street is ten times more dangerous than smoking 10 cigarettes a day (BMA 1990), ten times more dangerous than World War Two (Mueller and Stewart 2011), 75 times more dangerous than mountain climbing (BMA 1990), and 500,000 times more dangerous than trees in public places in the UK.

A QTRA of the 14 trees was undertaken by Mike Ellison in January 2012. He estimated the ROH to be 1 in 170,000 for the worst tree, and a $\mathrm{ROH}$ of 1 in 2,000,000 for the best tree (Table 1). The largest discrepancy occurred in the estimation of probability of failure. The fact that two licensed QTRA practitioners can calculate a ROH that is more than 8,000 times higher than that derived by the developer of QTRA is a cause for concern.

\section{QUANTIFIED RISK ASSESSMENT AND DECISION MAKING}

There is a long history dating from the 1960s on QRA and its application to decision making. Applications of QRA range from assessing the safety of nuclear power plants and aircraft to road safety and flood protection. These applications arise because there is uncertainty and variability of the hazard and risks, the costs of failure are high or catastrophic, the costs of protection are also high, and public safety needs to be safeguarded. The decisions also affect many interested parties, so there is a need for a decision process that has scientific rigor, is transparent, and is acceptable to society. An understanding of the principles and practices that underpin QRA provide context for future developments to QTRA. The QTRA system should develop longer and more intensive training that includes the principles of QRA as a starting point.

The basic definition of risk has been standardized by international agreement (ISO 31000-2009). The process has been summarized as follows (Stewart and Melchers 1997) (Figure 3):

1. Define context. The system being examined, and the internal and external influences, must be known and defined.

2. Analyze hazard scenarios. Identification of what might go wrong, when and where.

3. Analyze risk.

$$
\text { Risk }=(\text { probability of failure }) \times(\text { consequences })
$$

Risk(orexpectedloss) maybegiveninterms of dollars, the number of human fatalities, or other quantifiable means for a specific time period (often annually). Typically, the probabilities are estimated from a combination of relevant data and statistics, predictive models of system reliability, and subjective judgments as a last resort.

4. Evaluate risks. Analyzed risk must be compared with criteria of risk acceptability.

5. Treat the risk. If the estimated risk exceeds the risk acceptance criteria, risk treatment is required. This may involve risk avoidance, risk reduction, or risk transfer.

6. Monitor and review. Usually a risk analysis presents only a snapshot of the risk at a particular point in time. Therefore, there is a need to monitor the system and to repeat the risk analysis at regular intervals.

While risks are seldom acceptable, they are often tolerable (or accepted reluctantly) if the benefits are seen to outweigh the costs [for a review, see Stewart and Melchers (1997) and Mueller and Stewart (2011)]. The benefit is the reduction in risk (damages or fatalities averted) associated with a decision, and the cost is the cost of the decision. The net benefit or net present value (NPV) is equal to benefit minus the cost equal to (e.g., Stewart 2010):

$$
\mathrm{NPV}=\mathrm{E}(\mathrm{B})+\Delta \mathrm{R}(\operatorname{Pr} \times \text { Consequences })-\mathrm{C}_{\Delta \mathrm{R}}
$$

where $\mathrm{E}(\mathrm{B})$ is the expected benefit from the decision not directly related to mitigating the risk; $\operatorname{Pr}$ is the probability of failure, assuming no risk mitigating measures; and Con-

Table 1. Results of QTRA for a single tree in Laman Street (Newcastle).

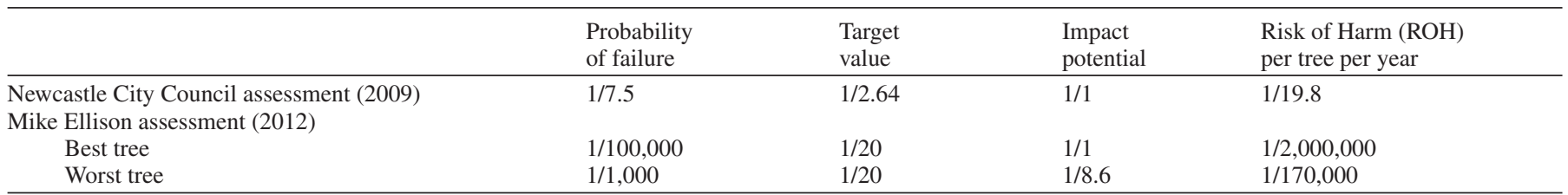




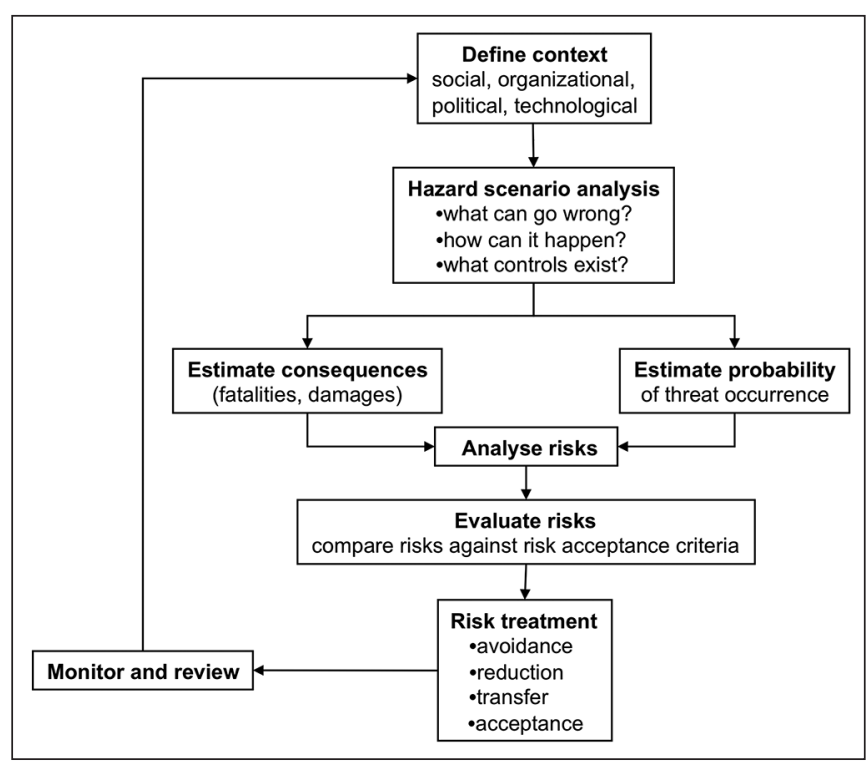

Figure 3. Risk assessment process.

sequences is the loss or consequence if failure occurs. The reduction in risk $(\Delta R)$ is the degree to which the decision or risk mitigating measures reduces the likelihood of failure and/or the losses sustained in a failure. The cost of reducing the risk, including opportunity costs, is $C_{\Delta R}$. This equation can be generalized for more detailed costs and damages.

It is important to recognize the issue of risk aversion (Faber and Stewart 2003; Stewart et al. 2011), and peer review-particularly for decisions that have the potential for political and public repercussions or where the assets have heritage, ecological, or cultural significance.

\section{QUANTIFIED TREE RISK ASSESSMENT}

\section{Calculation of Risk of Harm}

The probability of failure is the most subjective parameter to quantify when estimating Risk of Harm. According to the QTRA User Manual V3.06 (2012), there is an order or more of magnitude between each probability of failure range used on the QTRA calculator, starting from 1/1 and ranging to $1 / 1,000,000$. The QTRA User Manual (2007) points out that trees that have a low probability of failure "are at significant risk of failure only during very extreme weather events"; a statement supported by the observations of Guggenmoos (2009) in relation to damage of overhead power lines following catastrophic storm events in North America.

There seems to be little guidance for QTRA practitioners on how to assess the probability of failure. There are no instructions on how to undertake a statistical analysis of tree failures, how likelihoods may be estimated from wind speed and rainfall records (if these are the hazards contributing to failure), how mode of failure affects failure probabilities, how to estimate 90 th or 95 th percentile confidence intervals on predictions, or how to extrapolate probability of failure per tree to a group of trees (see Equation 2 to Equation 5). At this moment, the QTRA process of estimating probability of failure is subject to a degree of uncertainty because of the complex variables involved in tree biomechanics and tree failure, variable weather conditions, and varying levels of expertise of the assessors.

There is also a need to compile datasets on tree failures and failure rates in a format suitable for benchmarking. The International Tree Failure Database, for example, may be very useful for determining the number of failed trees, but a calculation of probability of failure (failure rate) requires also the number of unfailed trees, and the time period over which failures were observed (see Equation 10).

Benchmarking allows the predicted probability of failure to be compared to known statistics of failure obtained from relevant datasets. For example, is the assessed tree likely to be 10 times more likely to fail than an average tree, about the same, or 10 times less? Probability of failure may also increase with time if deterioration is observed, or perhaps those that have failed were weaker and so remaining trees are less vulnerable. Calculated risks will be most sensitive to probability of failure, and more scientific approaches and detailed guidelines are needed to better estimate this parameter.

The QTRA guidelines provide significantly more detailed instructions on quantifying target value or likelihood of impact. This is to be expected since it is not particularly difficult to assess the likelihood that people or vehicles will be under a tree at any point in time. In a busy street, it will be approximately $50 \%-100 \%$, and for a park, maybe $10 \%-20 \%$. Either way, any estimate will be accurate to $\pm 10 \%-20 \%$.

One issue that needs further elaboration is that trees are most vulnerable during periods of high wind and/or rain. These are circumstances where many people avoid the outdoors, thus reducing the target value considerably. Although the influence of weather is not discussed by Ellison (2005), it is discussed and some guidance is provided by the QTRA User Manual (2012).

The guidelines for impact potential are quite prescriptive, and are based on size of tree part likely to impact the target. Impact potentials vary from $1 / 1(100 \%)$ for a $450 \mathrm{~mm}$ diameter tree part to $1 / 2,500$ for a $10-25 \mathrm{~mm}$ tree part. If a tree or tree part were to fall, and a person was under the tree at the time, there will not be $100 \%$ surety of harm to the person no matter how large the tree-part. A tree has a large canopy, and a tree could fall away, or a tree-part could be on the opposite side from where a person is standing. Therefore, the upper limit of $100 \%$ seems too high and a more reasonable upper limit may be, say, $25 \%$ or $50 \%$, depending on the size of the tree. Impact potentials would seem to be over-estimated.

Finally, there is some evidence that results from a QTRA are highly subjective. Norris (2007) asked twelve experienced arborists to assess eight trees using eight different risk assessment methods (Figure 4). For QTRA, the Risk of Harm ranged from $1 / 19$ to $1 / 128$ million. The lowest and highest values were obtained from QTRA licensed practitioners. The range in probability of failure was $1 / 2$ to $1 / 50,000$. Such a large discrepancy should be a concern, as should the discrepancies between the two licensed QTRA practitioners and Ellison, who developed QTRA, in the case of the Laman Street fig trees.

\section{Risk Acceptance Criteria}

If the ROH exceeds 1 in 10,000, then the QTRA process deems that the risk is "unacceptable," and remedial action is needed to reduce the risk to an acceptable level (Ellison 


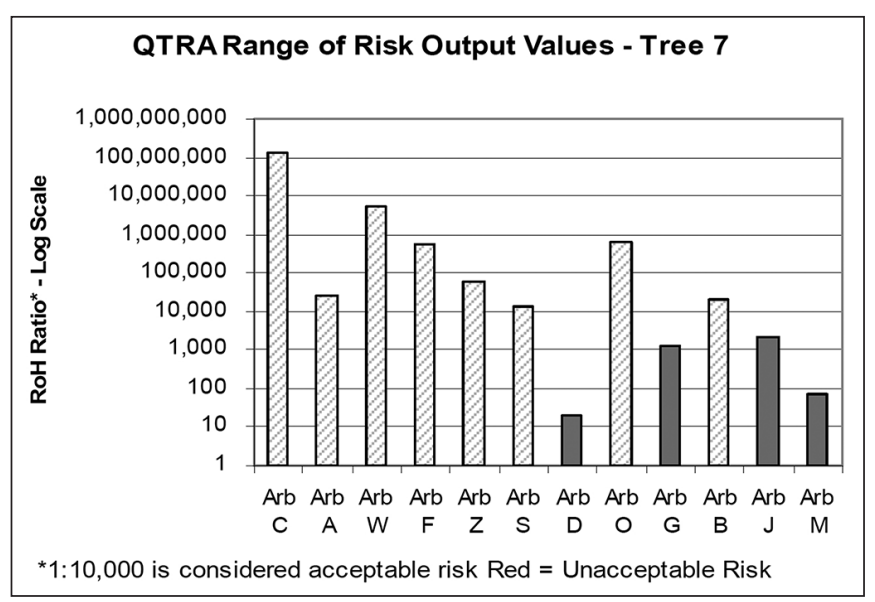

Figure 4. Range of Outcomes Using QTRA (Norris 2007).

2005). In principle, this risk acceptance criterion has much merit, but may be viewed as prescriptive. There is much evidence that annual fatality risks that exceed 1 in 1,000 are unacceptable, and that risks between 1 in 1,000 and 1 in 1 million may be acceptable to government and asset owners if the benefits outweigh the risks (Stewart and Melchers 1997) (Figure 5). There is no clear consensus about at precisely what level risks become unacceptable, so any prescribed safety goal needs to be interpreted with some flexibility. Ellison (2005) notes that "the hazard could confer benefits that might be set against the risk of harm." This implies a cost-benefit assessment, but the QTRA process does not offer guidance on how a cost-benefit analysis should be undertaken. The two cost-benefit examples to follow are provided to illustrate some key cost-benefit assessment concepts.

\section{Example 1: Net benefit of tree removal}

First, assume that tree removal is the recommended decision and that this will cost $\$ 10,000$ per tree. If this cost is spread over years $(\mathrm{T})$, then the annual cost discounted to present values is

$$
C_{A}=\frac{C_{T}}{\sum_{t=1}^{T} \frac{1}{(1+r)^{t}}}
$$

where $\mathrm{C}_{\mathrm{T}}$ is the total cost and $\mathrm{r}$ is the discount rate. If costs are annualized over $\mathrm{T}=10$ years at $\mathrm{r}=3 \%$, then this gives a present value of approximately $\$ 1,200$ per year. This might be viewed as a direct cost. However, an opportunity cost might also be associated with loss of amenity (e.g., shade, viewpoints, property value), which might amount to $\$ 1,000$ or $\$ 5,000$ per year.

The benefit of tree removal is that it will remove all risk, and so $\Delta \mathrm{R}=100 \%$. Another benefit of tree removal is that it may eliminate root damage to pavement and services, producing maintenance savings of $\$ 250$ per year. If a tree were to fail, the losses would be damage to adjacent property and loss of life totaling $\$ 5$ million.

All costs are converted to annual costs to ensure consistency of units. All values are illustrative only to help explain parameters and tradeoffs between costs and benefits. The NPV or net benefit for tree removal (Equation 7) is as follows:

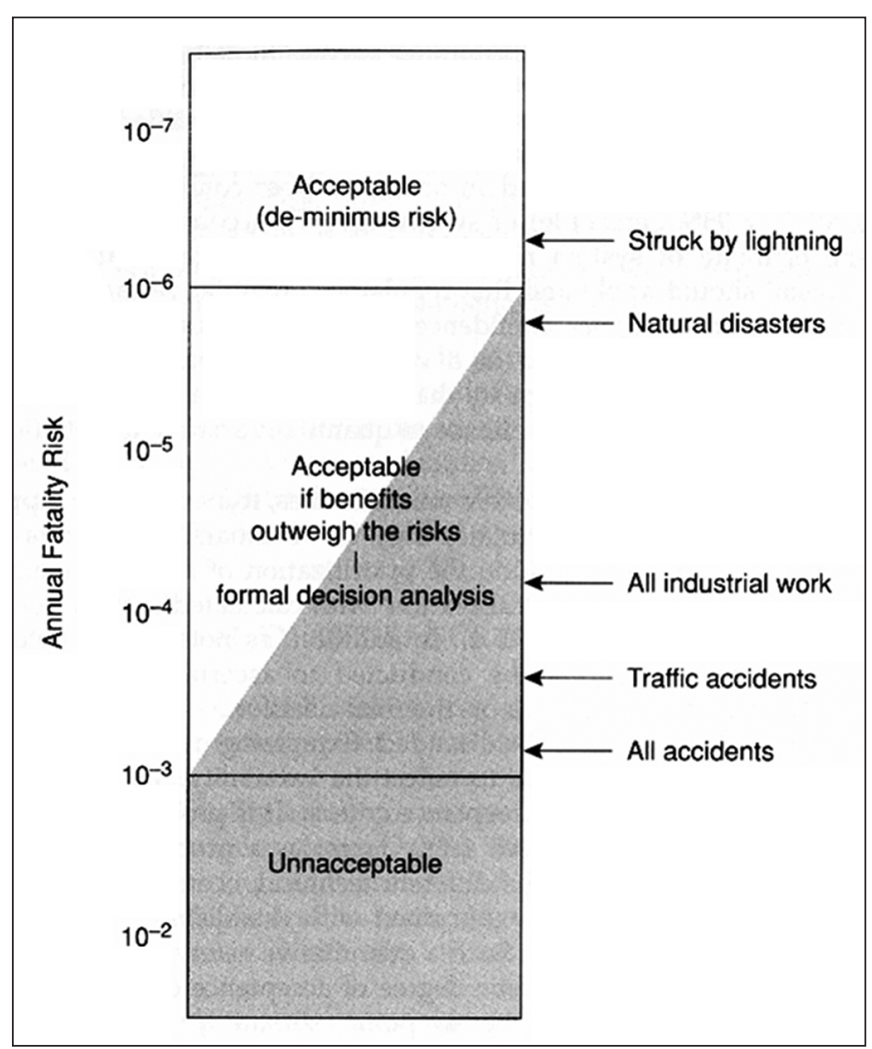

Figure 5. Generally agreed risk acceptance criteria for annual fatality risks (Stewart and Melchers 1997).

[9]

$$
\mathrm{NPV}=\mathrm{E}(\mathrm{B})+\Delta \mathrm{R}\left(\mathrm{ROH} \times \mathrm{C}_{\text {loss }}\right)-\mathrm{C}_{\Delta \mathrm{R}}
$$

where $\mathrm{ROH}=$ annual risk of harm per tree, $\mathrm{E}(\mathrm{B})=\$ 250$ per year (no root damage to infrastructure), $\Delta \mathrm{R}=100 \%$ (tree removal eliminates all risk), $\mathrm{C}_{\text {loss }}=\$ 5$ million (consequences of tree failure), and $C_{\Delta R}=\$ 1,200$ per year (cost of tree removal and no loss of amenity), $C_{\Delta R}=\$ 2,200$ per year (cost of tree removal and $\$ 1,000$ loss of amenity), and $C_{\Delta R}=\$ 6,200$ per year (cost of tree removal and $\$ 5,000$ loss of amenity).

Figure 6 and Table 2 show that net benefit varies as a function of $\mathrm{ROH}$ for losses of amenity of $\$ 0, \$ 1,000$, and $\$ 5,000$ per year. If $\mathrm{ROH}$ is $1 / 100$ then net benefit of tree removal is $\$ 44,000-\$ 49,000$, with net benefit highest when there is no loss of amenity. When $\mathrm{ROH}=1 / 1,000$ then the net benefit of tree removal reduces to $\$ 4,050$ and $\$ 3,050$ for loss of amenity of $\$ 0$ and $\$ 1,000$, respectively. However, when $\mathrm{ROH}=1 / 1,000$ and loss of amenity is $\$ 5,000$ per year, then there is not a net benefit of tree removal, but a net loss of $\$ 950$ per year. A lower $\mathrm{ROH}$ of $1 / 10,000$ produces net losses irrespective of level of loss of amenity. To be sure, more detailed analyses are possible, but this example shows that even if $\mathrm{ROH}$ exceeds the prescribed QTRA safety goal of $1 / 10,000$, there can still be a net benefit to retaining a tree once all costs and benefits of tree removal are considered. 


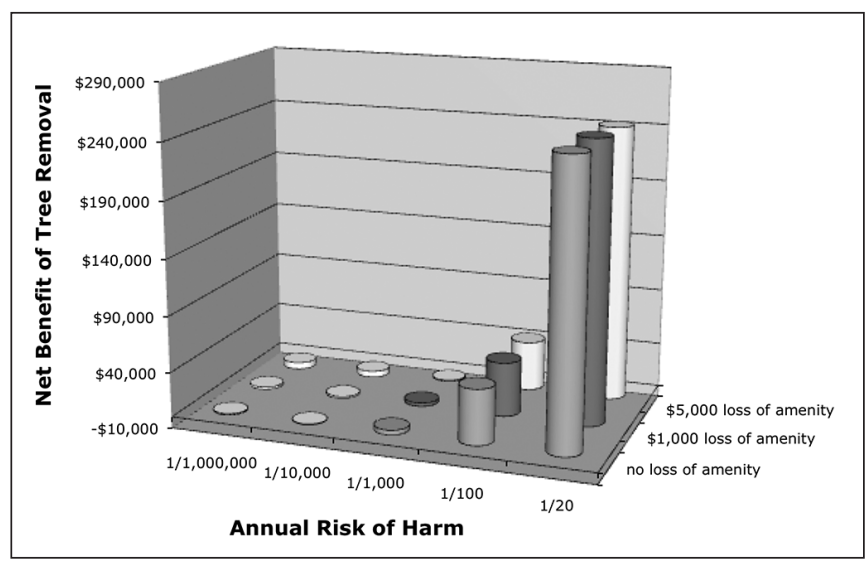

Figure 6. Net benefit of tree removal.

Table 2. Net benefit of tree removal as function of Risk of Harm (ROH) and cost of tree removal including opportunity costs $\left(C_{\triangle R}\right)$. All currency is represented in Australian dollars (AUD\$).

\begin{tabular}{llll}
\hline & \multicolumn{2}{l}{$\begin{array}{l}\text { Cost of tree removal including } \\
\text { opportunity costs }\left(\mathrm{C}_{\Delta \mathrm{R}}\right)\end{array}$} \\
\cline { 2 - 4 } $\begin{array}{l}\text { ROH per tree } \\
\text { per year }\end{array}$ & $\$ 1,200$ & $\$ 2,200$ & $\$ 6,200$ \\
\hline $1 / 20$ & $\$ 249,050$ & $\$ 248,050$ & $\$ 244,050$ \\
$1 / 100$ & $\$ 49,050$ & $\$ 48,050$ & $\$ 44,050$ \\
$1 / 1,000$ & $\$ 4,050$ & $\$ 3,050$ & $-\$ 950$ \\
$1 / 10,000$ & $-\$ 450$ & $-\$ 1,450$ & $-\$ 5450$ \\
$1 / 100,000$ & $-\$ 900$ & $-\$ 1,900$ & $-\$ 5,900$ \\
$1 / 1,000,000$ & $-\$ 945$ & $-\$ 1,945$ & $-\$ 5,945$ \\
$1 / 10,000,000$ & $-\$ 950$ & $-\$ 1,950$ & $-\$ 5,950$ \\
\hline
\end{tabular}

Note: Each entry represents benefit minus cost result for each ROH and value of tree amenity.

Entries that are positive would be considered cost-effective to implement risk mitigating measures.

\section{Example 2: Net benefit of risk mitigating measure}

Rather than removing the tree, it is possible to employ a risk mitigation strategy to reduce the exposure of people to a potential hazard. This might include, for example, restricting vehicle access to an adjacent road, redirecting pedestrian traffic, or closing the street on high wind days. The study authors assume a $75 \%$ reduction in target probability, equivalent to a risk reduction of $\Delta \mathrm{R}=75 \%$. The cost of risk mitigation measures may be $\$ 15,000$ per year. Maintenance costs associated with root damage to pavement and services costs $\$ 250$ per year. Hence, $C_{\Delta R}=\$ 15,250$ per year, and $\mathrm{C}_{\text {loss }}=\$ 5$ million as assumed above. A benefit of retaining the trees may be public amenity, which may vary from $E(B)=\$ 1,000$ to $E(B)=\$ 5,000$ per year.

Net Benefit is calculated from Equation 9 using the parameters described in Table 3 . If the $\mathrm{ROH}$ is $1 / 100$ or greater, then risk mitigating measures are cost effective. However, the benefits of such measures reduces as $\mathrm{ROH}$ decreases, even when the public amenity and benefit of retaining the tree is valued at $\mathrm{E}(\mathrm{B})=\$ 5,000$ per year. If the $\mathrm{ROH}$ is $1 / 100$, the net benefit for tree removal is $\$ 49,050$ (assuming no loss of amenity), and $\$ 22,500$ if risk mitigating measures are put in place that reduce risk by $75 \%$ (compare Table 2 and Table 3). It follows that a decision aimed at only maximizing net benefit would be to remove the tree-assuming that economic assessment is the sole criterion for decision making. However, if a decision was to retain the trees for non-quantifiable reasons (e.g., heritage value, tourism) then

Table 3. Net benefit of risk mitigation that reduces risk by $\Delta R=75 \%$. All currency is represented in Australian dollars (AUD\$).

\begin{tabular}{llll}
\hline & \multicolumn{3}{l}{ Value of tree amenity $\mathrm{E}(\mathrm{B})$ per year } \\
\cline { 2 - 4 } $\begin{array}{l}\text { Risk of Harm (ROH) per } \\
\text { tree per year without risk } \\
\text { mitigating measures }\end{array}$ & $\$ 0$ & $\$ 1,000$ & $\$ 5,000$ \\
\hline $1 / 20$ & $\$ 172,250$ & $\$ 173,250$ & $\$ 177,250$ \\
$1 / 100$ & $\$ 22,250$ & $\$ 23,250$ & $\$ 27,250$ \\
$1 / 1,000$ & $-\$ 11,500$ & $-\$ 10,500$ & $-\$ 6,500$ \\
$1 / 10,000$ & $-\$ 14,875$ & $-\$ 13,875$ & $-\$ 9,875$ \\
$1 / 100,000$ & $-\$ 15,213$ & $-\$ 14,213$ & $-\$ 10,213$ \\
$1 / 1,000,000$ & $-\$ 15,246$ & $-\$ 14,246$ & $-\$ 10,246$ \\
$1 / 10,000,000$ & $-\$ 15,250$ & $-\$ 14,250$ & $-\$ 10,250$ \\
\hline
\end{tabular}

Note: Each entry represents benefit minus cost result for each ROH and value of tree amenity.

Entries that are positive would be considered cost-effective to implement risk mitigating measures.

risk mitigating measures are also cost-effective and justifiable with a net benefit of at least $\$ 22,250$. Clearly, different cost inputs will lead to different results and decisions.

\section{Improvements to QTRA}

The priority for improvement lies in more accurate and robust assessment of failure probabilities, as this is the parameter in the risk equation subject to the highest uncertainty (and error). This means more scientific approaches are needed, and that results are benchmarked with known risks to ensure that results pass a reality check.

Hazard identification is an important first step to understand the cause of tree failure, and then the frequency and severity of these events. This might involve assessing the annual probability that a wind speed exceeds a certain value, or rainfall exceeds a specific value. Statistical and probabilistic models for natural hazards are well researched and documented. For example, Wang and Wang (2009) provide stochastic wind field models for most locations in Australia for cyclones and storms.

If the tree under consideration is similar in age, condition, and exposure to other trees, then the failure probability may be derived as

$$
\text { Probability of Failure }=\frac{\mathrm{n}(\text { failed trees over time period } \mathrm{T})}{\mathrm{N} \times \mathrm{T}} \text { per year }
$$

where $\mathrm{n}()$ is the number of failed trees over time period $\mathrm{T}, \mathrm{N}$ is the total number of failed and unfailed trees, and $\mathrm{T}$ is time measured in years. It is preferable to consider time periods in excess of one year, as this will average out the failure probability over time and is more likely to consider the effect of extreme events.

The larger the sample size $(\mathrm{N} \times \mathrm{T})$ the more confidence there is in the calculation. It follows from binomial theory that the $90 \%$ confidence limits of such as a result is

[11]

Probability of Failure $\pm 1.645 \sqrt{\frac{\text { Probability of Failure } \times(1 \text { - Probability of Failure })}{\mathrm{N} \times \mathrm{T}}}$

Taking the Laman Street figs as an example, if $\mathrm{n}$ (failed trees) is 2 over $\mathrm{T}=10$ years, and the total number of trees is $\mathrm{N}=16$, then the probability of failure given by Equation 10 is 0.0125 or 1/80. 
The $90 \%$ confidence interval for this estimate is $0.0125 \pm 0.0144$, which means that there is $90 \%$ probability that the probability of failure lies between 0.0 and 0.0269 (1/37). Calculations such as these help provide an indication of upper and lower bounds.

If statistically robust estimates of probability of failure are not available, then the probability of failure of the tree under consideration may be compared with an average tree where the probability of failure is known. For example, the probability of failure of trees in public places in the UK is at least 1 in 10 million (assuming target value and impact potential are unity) (HSE 2007; NTSG 2011). An assessment may then conclude that the tree has a risk that is 10 or 100 times higher than a typical tree, or perhaps less. This requires some subjectivity, but helps provide comparative risks.

The setting of risk acceptance in the QTRA process should be broadened to include cost-benefit or other decision theory considerations. Such considerations are particularly useful where the decision has repercussions well beyond ensuring public safety. Risk mitigating measures, such as site access restrictions and tree removal, can be assessed in a rigorous and methodical manner that aims to incorporate the costs and benefits of all interested parties.

A QTRA should use mean estimates for risk calculations as governments mandate risk-neutral risk assessments. While it may seem prudent to select conservative estimates, if the QTRA's three parameters are doubled, then ROH increases eight fold. If excessively conservative values are used at each opportunity then the calculated $\mathrm{ROH}$ becomes illogical.

A clear example of the consequence of not using the mean (or using the extreme conservative) occurred when an assessor of the figs in Laman Street determined that the probability of tree failure was 1 in 7.5 per tree per year. This figure was derived on the assumption that since two trees failed in 2007 then the likelihood of tree failure would be the same in the following year, disregarding the fact that the weather in 2007 was an extreme event with annual probability of approximately 5\% (Stewart 2012). The assessor also ignored the fact that for the previous several decades, no trees failed.

Decisions partially or fully based on QTRA can significantly affect the well-being of the public. Thus the decision-making process should include within it quality assurance measures and a peer review to add confidence to any decision made. Quality assurance procedures tend to focus on internal reviews. Peer review is an independent and critical review of risk analysis and risk assessment procedures and should obviously be conducted by recognized experts. If a peer review produces risks or recommendations that are in conflict with previous reports, then there should be an opportunity for all parties to see if a consensus can be reached. If not, then the decision-makers can decide if more studies are needed, or can make a decision recognizing lack of consensus and the use of alternate decision criterion to reach a decision.

Finally, while quantitative decision support tools, such as QRA and QTRA, hold some appeal to decision makers, they cannot capture the full and diverse range of societal considerations of risk acceptability. Therefore, a QTRA should be viewed only as an aid to decision support, where decisions about public safety will often require social, economic, cultural, environmental, political, and other considerations.

\section{CONCLUSIONS}

A QTRA should be subject to rigorous and independent review to judge the veracity of the calculated risks. The QTRA system should develop longer and more intensive training that includes the principles of QRA as a starting point. This could reduce the risk of wide discrepancies between individual QTRA users. There is also a need for any risk management process involving trees, not only to assess the risk but to consider the benefits provided by trees (i.e., to conduct a risk-based costbenefit analysis). While crude datasets relating to tree failures do exist, as with the International Tree Failure Database for example, considerable work is still required in this area. In the meantime, tree risk assessors should, as far as reasonably possible, rely on benchmarks to ensure that their assessments are not outside of the realms of reality and include at least some form of scientific rigor.

\section{LITERATURE CITED}

BMA. 1990. The BMA Guide to Living with Risk. The British Medical Association. Penguin Books, London, England.

Ellison, M.J. 2005. Quantified Tree Risk Assessment Used in the Management of Amenity Trees. Journal of Arboriculture 31(2):57-65.

Faber, M.H., and M.G. Stewart. 2003. Risk Assessment for civil engineering facilities: Critical overview and discussion, reliability engineering, and system safety 80(2):173-184.

Guggenmoos, S. 2009. Managing tree caused electric service interruptions. UAA Quarterly (Special Edition):4-9.

HSE. 2007. Agriculture Safety, LAC 23/22, Health \& Safety Executive/ Local Authorities Enforcement Liaison Committee (HELA), Health and Safety Executive. September 10, 2007.

ISO 31000-2009. Risk Management-Principles and Guidelines, International Organization for Standardization, Geneva, Switzerland, 2009.

Marsden, D. 2009. Assessment of Hill's Weeping Fig Ficus microcarpa var. hillii in Civic Cultural Precinct, Laman Street, Cooks Hill, Newcastle. August 7, 2009.

Matheny, N.P., and J.R. Clark. 1994. A Photographic Guide to the Evaluation of Hazard Trees in Urban Areas (2nd edition). International Society of Arboriculture, Champaign, Illinois, U.S.

Mueller, J., and M.G. Stewart. 2011. Terror, Security and Money: Balancing the Risks, Benefits and Costs of Homeland Security. Oxford University Press, Oxford and New York

Norris, M. 2007. Tree Risk Assessments: What Works - What Does Not - Can We Tell?, ISAAC Conference, Perth, 2007.

NTSG. 2011. Common sense risk management of trees - Guidance on trees and public safety in the UK for owners, managers, and advisers. National Tree Safety Group, Forestry Commission Publications.

Poll v Bartholomew. 2006. England \& Wales High Court [EWHC] Queen's Bench Division [QB] (Bristol: 4BS50384).

QTRA. 2012. User Manual V3.06, QTRA Ltd Licensed Product.

QTRA Newcastle. 2010. <www.newcastle.nsw.gov.au>

Schmidlin, T.W. 2009. Human fatalities from wind-related tree failures in the United States 1995-2007. Natural Hazards 50(1):13-25.

Smiley, E.T., B.R. Fraedrich, N. Hendrickson, and G. Percival. 2007. Tree Risk Management (2nd edition). FA Bartlett Tree Expert Company, Inc. 
Smiley, E.T., N. Matheny, and S. Lilly. 2011. Tree Risk Assessment. International Society of Arboriculture, Champaign, Illinois, U.S.

Stewart, M.G., and R.E. Melchers. 1997. Probabilistic Risk Assessment of Engineering Systems, Chapman \& Hall, London, England.

Stewart, M.G. 2010. Acceptable risk criteria for infrastructure protection. International Journal of Protective Structures 1(1):23-39.

Stewart, M.G., B.R. Ellingwood, and J. Mueller. 2011. Homeland security: A case study in risk aversion for public decision-making. International Journal of Risk Assessment and Management 15(5/6):367-386.

Stewart, M.G. 2012. Quantified Tree Risk Assessment: A Critical Review, Presented at 2012 Arboriculture Australia, UAAA \& SMA National Conference Hobart, April 27- May 2, 2012.

Wang, C-H., and X. Wang. 2009. Hazard of Extreme Wind Gusts in Australia and its Sensitivity to Climate Change. CSIRO National Research Flagship Climate Adaptation, May 2009.

Mark G. Stewart (corresponding author) Australian Professorial Fellow

Director, Centre of Infrastructure Performance and Reliability

The University of Newcastle

New South Wales 2308, Australia

mark.stewart@newcastle.edu.au

Dealga O'Callaghan, Ph.D.

Chartered Arboricultural Consultant

Dealga's Tree Consultancy Limited

Liverpool, England

Mark Hartley

Senior Consulting Arborist

Arborist Network

Sydney, Australia
Résumé. L'évaluation quantifiée du risque (Quantified Risk Assessment ou $Q R A$ ) a été largement utilisée en gestion du risque depuis les années 60 à la fois en aéronautique, dans l'industrie nucléaire, pour les plates-formes de forage, en traitement médical et dans l'industrie pharmaceutique. Le système de quantification du risque associé aux arbres (Quantified Tree Risk Assessment ou QTRA) est examiné en regard des principes liés à l'évaluation quantifiée du risque (ou QRA). Une étude de cas avec 14 figuiers à Newcastle en Australie a permis d'observer certaines limites avec le processus du QTRA ainsi que l'extrapolation des risques entre un arbre individuel et un groupe d'arbres. Il y a un besoin en regard d'un processus de gestion du risque lié aux arbres, non seulement pour évaluer le risque, mais aussi pour soupeser les bénéfices apportés par les arbres en fonction d'une analyse de ratio coût-bénéfice basée sur le risque. Les experts en risques devraient pouvoir compter sur des références solides afin de s'assurer que leur évaluation n'est pas hors des limites de la réalité ou encore de la rigueur scientifique.

Zusammenfassung. Die Quantifizierte Risikoabschätzung (QRA) ist seit den 1960ern weit verbreitet bei der Risikoverwaltung verschiedener Systeme angefangen bei Luftfahrt, Atomkraft und Bohrinseln bis hin zu medizinischen Behandlungen und pharmazeutischen Bereichen. Die Quantifizierte Baumrisikoabschätzung (QTRA) wurde hier unter Bezug auf die Prinzipien der QRA untersucht. Eine Fallstudie von 14 Feigenbäumen in Newcastle, Australien, illustrierte einige Einschränkungen des QTRA-Prozesses und extrapolierte die Risiken für einen einzelnen Baum innerhalb einer Baumgruppe. Es besteht ein Bedarf an Risikomanagement bezüglich Bäumen nicht nur um das Risiko zu bewerten, sondern auch um die Vorteile, die Bäume liefern, in einer risiko-basierten KostenNutzen-Bilanz zu evaluieren. Baumrisiko-Bewerter sollten sich an den Richtwerten orientieren, um sicher zu stellen, dass ihre Bewertung nicht außerhalb der Realität oder wissenschaftlicher Präzision steht.

Resumen. La Evaluación Cuantificada de Riesgos (QRA, por sus siglas en inglés) es de amplio uso en la gestión de riesgos desde la década de 1960 para los sistemas, desde la aviación, la energía nuclear y las plataformas en alta mar, hasta los tratamientos médicos y los productos farmacéuticos. El sistema de Evaluación Cuantificada de Riesgos para los Árboles (QTRA, por sus siglas en inglés) es examinado teniendo en cuenta los principios de QRA. Un estudio de caso de 14 higueras en Newcastle, Australia, muestra algunas limitaciones del proceso QTRA extrapolando los riesgos de un árbol a un grupo de árboles. Es necesario para cualquier proceso de gestión del riesgo que implica a los árboles, no sólo evaluar el mismo, sino también el peso de los beneficios proporcionados por los árboles en un análisis de costo-beneficio basado en el riesgo. Los evaluadores de riesgos del árbol deben confiar en puntos de referencia para garantizar que su evaluación no se encuentra fuera de los dominios de la realidad o del rigor científico. 